\title{
The Development and Application of Genetic Markers for Giant Freshwater Prawns Macrobrachium Rosenbergii by Microsatellites
}

\author{
Siripavee Charoenwattanasak*, Rakpong Petkham, Aruneepong Srisathapom and Pornthep Niamphithak \\ Khon Kaen University, Department of Fisheries, Faculty of Agriculture, Khon Kaen, Thailand
}

\begin{abstract}
This article reports the development of microsatellite primers for giant freshwater prawns (Macrobrachium rosenbergii), using the genome library for this type of prawns and biotinylated probe in isolating six types of DNA fragments with base sequence repeats, namely (AG)10, (TG)10, (CAA)10, (CAG)10, (GAT)10 and (TAC)10. Four clones harboring microsatellites were chosen, namely SH2-9F, SH2-10C, SH2-11D and SH3-11G. Base sequencing found no microsatellite sequences. Four pairs of primers were designed, namely DTLSH 7, DTLSH 8, DTLSH 9 and DTLSH 12, respectively. These primers were tested on the DNA of giant freshwater prawns, and DNA band sizes were found to be 131, 174, 210 and 193 per 205 bp, respectively. The developed microsatellite primers may be used in conjunction with primers for other types of prawns. Genetic diversity checking of giant freshwater prawns in Thailand showed that their population in Thailand may be classified into two groups: one with the closest genetic relationship being those from Khon Kaen, Samut Songkhram and Ang Thong provinces while the other with similar genetic characteristics were those from these three provinces as compared to those from Surat Thani province.
\end{abstract}

Keywords: Giant freshwater prawn; Microsatellite; Genetic marker

\section{Introduction}

Macrobrachium rosenbergii, or its generic name the giant freshwater prawn, is the freshwater prawn popularly raised in India, in the Southeast Asian countries, in Northern Australia and in certain parts of the Pacific and Indian Oceans. In Thailand, the aquaculture part is considered an industry with great significance to the country as prawns can be a principal aquacultural protein source that is high in nutritional values. In addition, they are one of Thailand's top export goods in terms of income earnings. Their domestic productivity enhancement, however, is without stability, and there are some limitations in their production. Augmented growth rates of prawns would be another indicator of productivity potentials. This condition partly requires improvement in genetic characteristics [1]. Selection of suitable stocks in breeding programs is affected by genetic variation of any given animal population. Development of microsatellite markers will, therefore, be very useful in identifying polymorphisms and even in the mapping of a sample population from the same species. The polymorphisms of these markers come from their different numbers of repeats. Microsatellite markers are codominant-hence can detect the difference between homozygotes and heterozygotes. At present, microsatellites in giant freshwater prawns have been developed from two groups; one of which is the eastern form [2] with six pairs of primers having been developed [3]. The other group is the western form [2]. Thailand's giant freshwater prawns have been classified in this latter group, which has so far had 11 pairs of microsatellite primers [4]. These, however, are not sufficient for use as molecular markers for giant freshwater prawns in Thailand. Its data base for development of additional microsatellite primers to cover other parts of the prawns' genome would maximize the usage and accuracy in the breeding programs in the future.

\section{Material and Methods}

1. Collection of sample stocks of giant freshwater prawns general in Thailand, DNA extraction of the prawns (Macrobrachium rosenbergii) and DNA quantification, using electrophoresis.

2. Digestion and ligation of liker to DNA fragments. The extracted DNA or genome was digested, using a restriction enzyme as follows:
Approximately $500 \mathrm{ng}$ of the genomic DNA were digested using the restriction enzyme Tru 9I or MseI and ligated using T4 ligase and MseI-Adaptor at $37^{\circ} \mathrm{C}$ for seven to eight hours or overnight. After the incubation and digestion with the restriction enzyme, the DNA was then made 10-20-fold diluted in Ultrapure water.

3. Capture of specific repetitive sequences with biotinylated oligonucleotides. Probes were constructed from base sequences with multiple repetitions at the same locations, such as (AG) 10 or (CAA) 10 , as follows: Utilized probes consisted of six types of biotinylated oligo SSR, namely (AG)10, (TG)10, (CAA)10, (CAG)10, (GAT)10 and (TAC) 10. The oligo SSR contained conjugated biotin at the 5 terminal of each strand. The probe/DNA fragments ratio during probe preparation prior to hybridization was $10 \mathrm{pmol} / 1.0 \mathrm{pmol}$. Subsequently, each biotinylated oligo SSR was mixed with $1 \mathrm{ml}$ of Streptavidin Magnetic Sphere Paramagnetic Particles (SA-PMPs). The streptavidin binds to biotin while its other end binds to magnetic particles. The mixture was left at room temperature for two hours and then washed with 5X SSC twice while using Magnetic Sphere Magnetic Separation Stands (MSMSS) to hold the biotinylated oligo SSR bound to the streptavidin. Excessive biotinylated oligo SSR was removed by washing, and the desired part was subsequently hybridized with the DNA.

a. In mixing the DNA with the streptavidin-biotinylated oligo SSR complex, the former was first separated into single strands, applying heat at $95^{\circ} \mathrm{C}$ for 10 minutes. It was immediately put on ice and then mixed with SSC at a concentration adjusted to $6 \mathrm{X}$. The temperature

*Corresponding author: Siripavee Charoenwattanasak, Khon Kaen University Department of Fisheries, Faculty of Agriculture, Khon Kaen, Thailand, Tel: 66-819750669; E-mail: kobkaew@kku.ac.th

Received October 30, 2014; Accepted November 17, 2014; Published Janaury 20, 2015

Citation: Charoenwattanasak S, Petkham R, Srisathapom A, Niamphithak P (2015) The Development and Application of Genetic Markers for Giant Freshwater Prawns Macrobrachium Rosenbergii by Microsatellites. J Aquac Res Development 6: 295. doi:10.4172/2155-9546.1000295

Copyright: (c) 2015 Charoenwattanasak S, et al. This is an open-access article distributed under the terms of the Creative Commons Attribution License, which permits unrestricted use, distribution, and reproduction in any medium, provided the original author and source are credited. 
used was dependent on the probes' melting temperatures: $55^{\circ} \mathrm{C}$ for (AG) 10 and $(\mathrm{TG}) 10$, and $65^{\circ} \mathrm{C}$ for (CAA) 10 , (CAG) 10 , (GAT) 10 and (TAC) 10. The reaction was allowed to take place for approximately 10-12 hours or overnight. Subsequently, only the DNA that had been bound to streptavidin-biotinylated oligo SSR complex was selected, using MS-MSS to draw it to the sides of tubes, and the supernatant removed. The next step was to wash with low and high stringency solutions to remove any remaining unwanted DNA and to clean the desired DNA. A subsequent step was to separate the latter from the streptavidin-biotinylated oligo SSR complex by adding $0.15 \mathrm{~N} \mathrm{NaOH}$ and leaving the mixture at room temperature for approximately 30 minutes. MS-MSS was then used to draw the streptavidin-biotinylated oligo SSR complex to the sides of tubes. All supernatant was transferred to new tubes and neutralized by adding $1 \mathrm{~N}$ acetic acid and TE buffer. The obtained DNA was subsequently washed clean, using High Pure PCR isolation kit (Boehringer).

4. Library construction and cloning, using pGEM-T Easy kit (Promega) as follows:

a. Vector used in the ligation to the DNA was pGEM-T Easy (Promega) sized approximately to $3 \mathrm{~kb}$ at the concentration of $50 \mathrm{ng} / \mu \mathrm{l}$. The ligation step utilized the insert:vector ratio of 3:1 with the following formula in calculating the quantity of insert to use.

$$
\text { b. } \frac{\text { Insert size }(k b) x \text { vector quantity }}{\text { Vector size }(k b)} \chi \frac{3}{1}=\text { Insert quantity to use }
$$

c. A total $10 \mu \mathrm{l}$ of ligation reaction comprised $25 \mathrm{ng}$ of pGEM-T Easy, X ng of insert, $5 \mu \mathrm{l}$ of $2 \mathrm{X}$ Rapid Ligation buffer and 3 weiss units of T4 ligase 3. The reaction was left at $4^{\circ} \mathrm{C}$ overnight. The next step of transformation employed electroporation, using E. coli strain DH 10B as host and plating on selective agar medium $(100 \mu \mathrm{g} / \mathrm{ml}$ ampicillin, $100 \mu \mathrm{M}$ IPTG and $40 \mu \mathrm{g} / \mathrm{ml} \mathrm{x}$-gal). The obtained white colonies were checked for the insert size, using PCR with primers M13 forward and M13 reverse. Electrophoresis was used to compare with control, which consisted of a blue colony, and molecular weight markers. Only white colonies with inserts sized $500 \mathrm{bp}$ and larger were chosen for the sequencing step.

\section{Screening of positive colonies by PCR}

a. Dot blot hybridization of oligonucleotide probes as per the method described by Sambrook [5].

\section{DNA sequencing of positive clones:}

7. The desired colonies were chosen to be cultured in a broth containing $1 \mathrm{~mL}$ of ampicillin $(100 \mu \mathrm{g} / \mathrm{ml})$ at $37^{\circ} \mathrm{C}$ for approximately three to five hours. The cell culture underwent PCR, of which $20 \mu \mathrm{l}$ comprised 0.25 pmol of M13 primers (forward and reverse), $100 \mu \mathrm{M}$ dNTPs, PCR buffer (100 mM Tris- $\mathrm{HCl}$ (pH 9.0), $500 \mathrm{mM} \mathrm{KCl,} 1.5 \mathrm{mM}$ $\mathrm{MgCl} 2$ ) and $1 \mu \mathrm{Taq}$ DNA polymerase, in GeneAmp PCR System 9700 (Applied Biosystems). Its programmed temperatures were as follows: one round of $94^{\circ} \mathrm{C}$ for three minutes, $94^{\circ} \mathrm{C}$ for 30 seconds, $55^{\circ} \mathrm{C}$ for 30 seconds, 35 rounds of $72^{\circ} \mathrm{C}$ for two minutes each round and one round of $72^{\circ} \mathrm{C}$ for seven minutes. After the reaction was complete, the PCR product concentrations and DNA base sequences were determined.

8. Sequencing analysis, using dye terminator cycle sequencing and ABI PRISM 377 DNA sequencer (PE Biosystems).

9. Primer design was based on the determined base sequences, using Gene Fisher interactive primer design software or Primer 3 in designing primers for use in DNA amplification. The SSR part was designed based on flanking region of that SSR strand, taking into account the length of oligonucleotides, the melting temperature and $\% \mathrm{G}+\mathrm{C}$ content. In addition, primers can be designed using such computer software as Primer Express (Perkin-Elmer), Prophet and also online design software. For example, website of http://www-genome. wi.mit.edu/cgi-bin/primer/primer3.cgi/ can check characteristics of primers that have been designed by calculation on http://www.genosys. com/. In the primer design, however, it is required that the location to be designed by the software should be quite far away from the SSR part; that is, approximately 30-50 bases away. Some primer may be less far away, but the distance should not be shorter than the primer length, and the base repeats found at that location should not be of more than three bases, particularly A and T. Primers were synthesized after obtaining the desired DNA base sequences for use the in primer design for the subsequent amplification of DNA, with base repeats as shown in Figure 1. The desired sequences comprised two short DNA strands; each of which was 18-25-base long and contained approximately 35-60\% GC. In addition, each strand had to have a melting temperature between $55-65^{\circ} \mathrm{C}$

10. Primer testing and optimization.

\section{Results}

\section{Genomic DNA preparation}

The results of DNA extraction from giant freshwater prawns are demonstrated in Figure 2. Comparing with lambda DNA, which was used as a marker, the DNA concentration ( $\mathrm{SH}$ ) was approximately 50 $\mathrm{ng} / \mu \mathrm{l}$, which were sufficient for test in the next step.

DNA (100, 300, 500 and 1,000 ng, respectively); SH, DNA extracted from prawn samples

\section{DNA fragments preparation and adaptor-ligated DNA}

After the genomic DNA of the prawns was digested with the restriction enzyme Tru 9I or MseI and ligated with MseI-Adaptor, it was found that the prawn DNA samples were on all three A-lanes. The enzyme was able to digest the DNA completely, as illustrated in Figure 3.

Subsequently, DNA was amplified, using PCR technique by first making the ligated DNA approximately 10-20-fold diluted to 10-20 $\mu \mathrm{l}$ In the PCR, the initial DNA was able to bind to the adaptor. One base

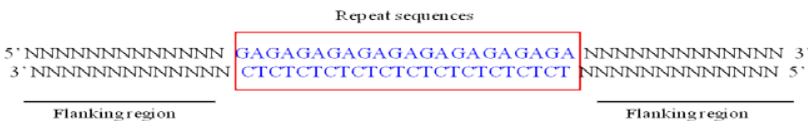

Figure 1: Locations on DNA strands for use in primer design.

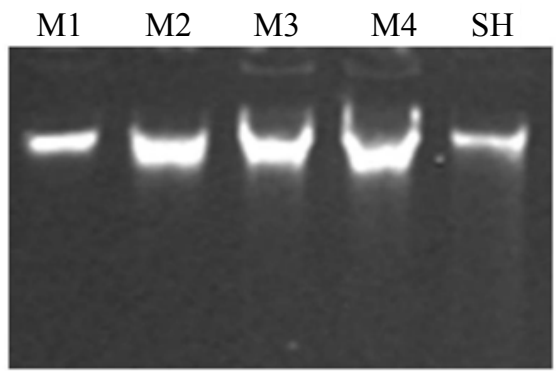

Figure 2: Quantification of DNA extracted from giant freshwater prawns: M1-M4, lambda 
Mse I adaptor 5, GACGATGAGTCCTGAG 3,
3' TACTCAGGACTCAT 5'

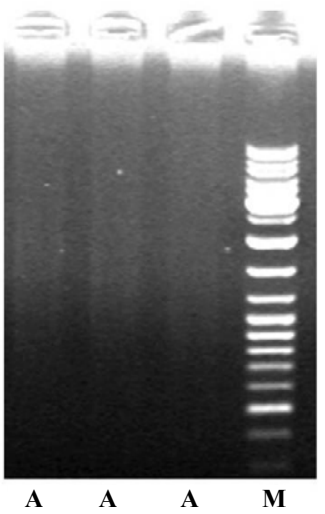

Figure 3: Bands giant freshwater prawn DNA obtained from digestion and adaptor-ligated step. A, digested DNA; M, Kb leader.

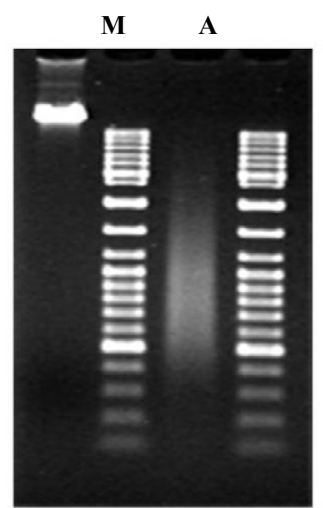

Figure 4: DNA characteristics of giant freshwater prawns after DNA amplification. A, amplified DNA; M, Kb leader.

for use in selection was added to the 3 '-end. Figure 4 shows the results of DNA amplification as seen by the more intense color bands on lane A than those in Figure 3.

\section{Enrichment}

Using six types of biotinylated oligo SSR probes, being (AG)10, (TG) 10, (CAA)10, (CAG)10, (GAT) 10 and (TAC)10. This step enabled DNA enrichment.

\section{Amplification}

The DNA obtained from the enrichment step was single-strand DNA, which could not be ligated into plasmid. The DNA, therefore, had to go through PCR, using primer MseI-5'GAT GAG TCC TGA GTA ANNN3', to become double-strand DNA. The amplified DNA was to be precipitated, using $1 / 10 \mathrm{~V} \mathrm{NaOAc}(\mathrm{pH} 5.2$ ) and $2 \mathrm{~V} 95 \%$ $\mathrm{EtOH}$, left at $-80^{\circ} \mathrm{C}$ for approximately one hour and centrifuged at $14,000 \mathrm{rpm}$ for 20 minutes. The precipitate was washed with $70 \% \mathrm{EtOH}$ twice, air-dried at room temperature and reconstituted with water. The resulting solution was measured in a spectrophotometer for use as insert DNA in the subsequent step.

\section{Library construction}

The prawn genome library was constructed for use in screening. The yielded white colonies were checked for the insert size. Electrophoresis was utilized to compare with the control, which was a blue colony, and molecular weight markers. Only the white colonies with inserts sized $500 \mathrm{bp}$ and larger were chosen for the sequencing step.

\section{Sequencing and primer design}

At this stage, four clones were found that were expected to harbor microsatellites and thus checked and sequenced. All four clones contained repetitive base sequences that did not match the desired microsatellites, as demonstrated in Figure 5. Primers were designed, based on the location with the most repeats. Starting from clone 1 , these were clone 1: $\mathrm{SH} 2-9 \mathrm{~F}$, primer designation: DTLSH 7; clone 2: SH2-10C, primer: DTLSH 8; clone 3: SH2-11D, primer: DTLSH 9 and clone 4: SH3-11G, primer: DTLSH 12. The base sequences of all four pairs of primers are described in Table 1. The developed primers are, nevertheless, considered an initially essential and important tool to be investigated into their application in further biotechnological basic research as regards prawns. The obtained primers are considered very appropriate for use in the research on prawns as they have been developed from the genomic part of giant freshwater prawns.

\section{Primer testing}

The synthesized primers were tested with the following DNA: first, DNA of giant freshwater prawns (genomic DNA) used in the initial step, as a positive control. Secondary, DNA of unknown giant freshwater prawns and finally, DNA of giant tiger prawns.

Ten $\mu$ of reaction comprised 1 and $5 \mathrm{ng}$ of starting DNA, forward and reverse primers of $0.5 \mu \mathrm{M}$ each, $1 \mathrm{X}$ PCR buffer (100 mM Tris$\mathrm{HCl}$ (pH 9.0), $500 \mathrm{mM} \mathrm{KCl}$ ), $2 \mathrm{mM} \mathrm{MgCl}, 200 \mu \mathrm{M}$ dNTPs and 0.2 unit of Taq DNA polymerase. It was put in a pre-set temperature controller (GeneAmp ${ }^{\oplus}$ PCR System 9700; Applied Biosystems), using the following temperatures: one round of $94^{\circ} \mathrm{C}$ for three minutes, $94^{\circ} \mathrm{C}$ for 30 seconds, $60^{\circ} \mathrm{C}$ for 30 seconds and 40 rounds of $72^{\circ} \mathrm{C}$ for one minute per each round and one round at $72^{\circ} \mathrm{C}$ for five minutes, as detailed in Tables 2 and 3. The PCR results were checked, using 4.5\% polyacrylamide gel followed by silver staining, and primer test results were obtained in Figure 6.

\section{Discussion}

Application in the Classification of Giant Freshwater Prawn Population in Thailand, giant freshwater prawn samples were collected from four provinces in Thailand, namely Khon Kaen (KK), Samut Songkhram (SK), Surat Thani (SR) and Ang Thong (AT). Twentyfive prawns were collected from each reservoir, totaling 100 samples. Data from the study on genetic diversity of giant freshwater prawns were analyzed by applying genetic distance values to the creation of a dendrogram among prawn population groups in Thailand by using UPGMA (unweighted pair-group method arithmetic means) [6] and NTSYSpc Version 2.10p. The giant freshwater prawn population in Thailand could be classified into two groups (Figure 7): one with the closest genetic relationship, namely those from Khon Kaen, Samut Songkhram and Ang Thong provinces, and the other with similar genetic characteristics, namely those from these three provinces as compared to those from Surat Thani province. This classification corresponds to Daungwongsa [7], who reported that the giant freshwater prawn population group from Khon Kaen was genetically close to that from Suphan Buri, a province in the Central region like Samut Songkhram and Ang Thong, and that the groups from Khon Kaen and Suphan Buri were genetically different from that from Surat Thani. The findings of the present study are consistent with the geographical distance; that 
Citation: Charoenwattanasak S, Petkham R, Srisathapom A, Niamphithak P (2015) The Development and Application of Genetic Markers for Giant Freshwater Prawns Macrobrachium Rosenbergii by Microsatellites. J Aquac Res Development 6: 295. doi:10.4172/2155-9546.1000295

\begin{abstract}
Clone 1 : SH2-9F / Primer : DTLSH 7
AGCTAAATTTATATGGGTTTAGAAAACGAAACCAAAAATATCTTACCTTACTTTGTTTCTATAAATTACAATGCCAACTTTCTGATAAAAG CCATTCAACTTGCAATATCATATATCTTAGGATACACATTCAATCAGCTGATACATCACTGCCTCTAATATTATCAACAACAAATTAT

Clone 2 : SH2-10C / Primer : DTLSH 8

AGAGAGAGAGAGAGAGAGAGGAAGTTGAGTAGTTGGACAGCAAGATGAAGAGATCCAGATAATAAAGGAGGTGAAGTACGAGGATCTAAAGGTGGA ACTGGGAGAAAACCACACAAAGAAATAAGAGTTAGAGATATTTGACAGCCAGAGTGAAGACAGGAAGCCAGAATGAAGGTAAAGTAAAAAGCTAAAA GTCGGTTCAGCTGGGGATGGAACTCCGGAATGGATGCCACAGACACGCTTTAGTAATGCCTGCAGTGCGCCACGTGAGGTGCACTGACGGCATTAC CCATAAGGGATCTTTAGAAAAACTCACTTACAAAGAAAGAAAAGCGAATAGCAGAGATTTCAGGCGAGTTGCAGCTTTTATTGAGACTTGTTGCTAGTC ACTGGATACTGTTGCTACGTCAGAGACGCCCAACACTTGTTGCTAGACGTGAGCATTGTCCCTGCACTTGACTTGGATGGCACTTGTTGCAAGGCTCC AGCCTTTGTTCTGTGAACAGCCGATTAGAAAAGAAGGGTTGCCCACCCAGTACTTCGAAAGCAATAATGTTTGTACTTTATTGCTCTAATCAGTACTGT AATTTTAGTTTTCATAAAGGATTATTTATCTTGGAACTAGTCTCTGATGGGACCGATTATGACCGAAATTTTTGGGT
\end{abstract}

Clone 3 : SH2-11D/ Primer : DTLSH 9

AGAGAGAGAGAGAGAGAGAGAGAGAGAGAGAGAGAGAATCATGCGATGCAGTGCTTCGTCGCTAACGGGAGCCACTTGCCATGTCCTAATTGTTGC CTTCGTCAGGGTTATGTTTTTGGCCCCCGTTCGTCTGGTTGTGAAAATAATCACGCACAAATTCAAGTGCGAATTATTACGCAAATCTGACCCAAGGT AGGACTCGTGACTGCAAAAAAAGTGATCAGGTTTTAGGAGAGACAGGGATGTAATTTTTGGGCAGATAGGGACCTTTAGTAAGCGGTTTTGCTCGGC TTTGTTTCGAGTTTTCCGGGCTTCAAAAACCCGAAATTCTATGCACCATTACTGTAATGAAATTCTGGTTGGAGGTTACGTCTTCTC

Clone4 : SH3-11G/ Primer : DTLSH 12

AAACAAAAGAATAGGATAAATAAATAAAAAAAAAGGAAATAACTGAACGAAAAAAGGCGATGACTATTTTTTTCAACTTGTTACGAATCGTTTTTGTAATC TTATATACCGCTGCCATATTTGATTTCTATATGCGCTGGCTGCATTGAAGCTCACTCGCTGGAAAACACGAATGGAAATTGATTAGAATGCTCGCTGGA ATAAAGAAACACTTGTGAAAGCTATATATATCTCTCTCTCCTATTTCTITCTCTCTCT TTCTTCTCTCTCTCCTTAGTCCTAAGCTTTIACTTCTTCAGA 作作 TGTGTGTGTGTGTGTGTGTGTAG

Figure 5: DNA sequencing in clone 1-4 of primer design.

\begin{tabular}{|c|c|c|c|c|}
\hline \multirow{2}{*}{ No. } & \multirow{2}{*}{ Primer name } & \multirow{2}{*}{ Clone } & \multicolumn{2}{|c|}{ Sequence } \\
\hline & & & Forward ( $5^{\prime}$ - & Reverse ( ${ }^{\prime}$ ' - \\
\hline 1 & DTLSH 7 & $\mathrm{SH} 2-9 \mathrm{~F}$ & AACGAAACCAAAAATATCTTACC & AGGCAGTGATGTATCAGCTG \\
\hline 2 & DTLSH 8 & $\mathrm{SH} 2-10 \mathrm{C}$ & GTACGAGGATCTAAAGGTGG & TACTAAAGCGTGTCTGTGGC \\
\hline 3 & DTLSH 9 & SH2-11D & AATTGTTGCCTTCGTCAGGG & AACAAAGCCGAGCAAAACCG \\
\hline 4 & DTLSH 12 & SH3-11G & TCGCTGGAAAACACGAATGG & AAAGCTTAGGGGTTGAGTGG \\
\hline
\end{tabular}

Table 1: The base sequences of primers.

\begin{tabular}{|c|c|c|c|c|c|c|}
\hline \multirow{2}{*}{ No. } & \multirow{2}{*}{$\begin{array}{c}\text { Primer } \\
\text { name }\end{array}$} & \multicolumn{4}{|c|}{ PCR Codition } & Product \\
\cline { 3 - 6 } & & Annealing & Mg Conc. & dNTPs & Cycle Number & $\begin{array}{c}\text { Size } \\
(\mathbf{b p})\end{array}$ \\
\hline 1 & DTLSH 7 & 60 & 2 & 200 & 40 & 131 \\
\hline 2 & DTLSH 8 & 60 & 2 & 200 & 40 & 174 \\
\hline 3 & DTLSH 9 & 60 & 2 & 200 & 40 & 210 \\
\hline 4 & DTLSH 12 & 60 & 2 & 200 & 40 & $193 / 205$ \\
\hline
\end{tabular}

Table 2: PCR reduction component and primer qualities.

is, Samut Songkhram is closest to Ang Thong, and both of them are in the Central region. The reason that the prawn population from Khon Kaen has similar genetic characteristics to that from Samut Songkhram and Ang thong may be that the prawn breeding or offspring has been moved from the Central region areas for the aquaculture in Khon Kaen area and has then escaped from culture houses or farms to natural reservoirs as well as the fact that the prawns have been allowed to live in natural reservoirs in order to increase productivity. Likewise, the prawn population from Khon Kaen has more genetic similarity to that from Surat Thani than that from Samut Songkhram and Ang Thong. This similarity is best understood by considering the genetic distance values as shown in Table 4, which would not seem to correspond to the longer geographical distance between Khon Kaen and Surat Thani as compared to the distance between Samut Songkhram or Ang Thong and Surat Thani. In addition, a confirmation of the classification of giant freshwater prawn population in Thailand by the neighbor-joining method [8] has revealed classification results that are not different from the UPGMA method. Dendrograms that classify the population using morphological averages and genetic distance values yield different results. This difference may result from the fact that the randomized

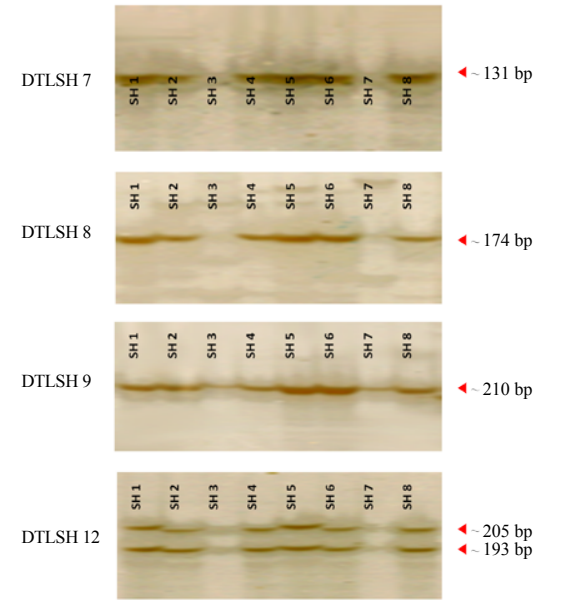

Figure 6: Bands of DNA from PCR products obtained from giant freshwater prawn samples by using the SSLP marker.

samples were very different in their growth. Also, morphological characteristics usually depend on the environment in each area, causing the classification to deviate from reality. This classification differs from what results from the use of apparent band data of microsatellite DNA in the classification since DNA is a component present in almost all cells in the same quantity. DNA from any tissues, growth phases or physiological conditions can, therefore, be examined without being dependent on the environment [9]. This approach provides greater accuracy than the population classification by morphology. 


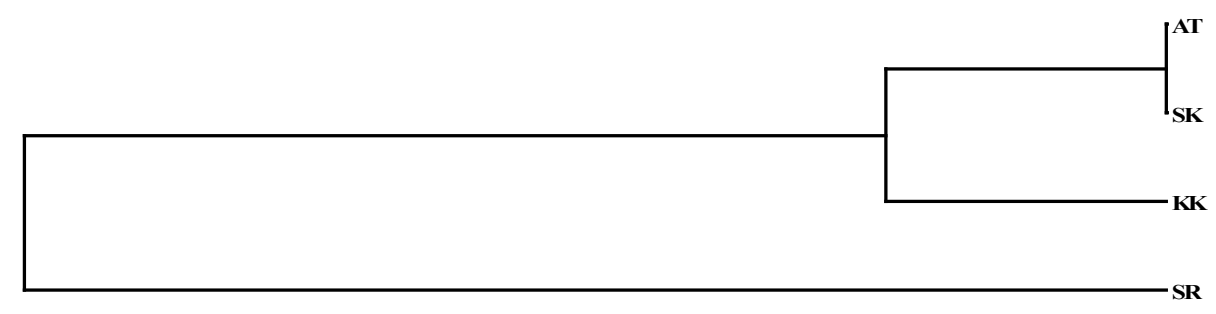

0.18
Coefficient

Figure 7: Dendrogram of giant freshwater prawn population in Thailand that is classified.

\begin{tabular}{|c|c|c|c|c|c|c|c|c|c|c|c|c|c|c|}
\hline \multirow[t]{2}{*}{ Oligo No. } & \multirow[t]{2}{*}{ Type } & \multirow[t]{2}{*}{ Purify } & \multirow[t]{2}{*}{ Name } & \multirow{2}{*}{\begin{tabular}{c}
\multicolumn{2}{c}{ Sequence } \\
5 ' -
\end{tabular}} & \multirow{2}{*}{\begin{tabular}{|r|} 
Total \\
bases \\
\end{tabular}} & \multirow[t]{2}{*}{ A } & \multirow[t]{2}{*}{ C } & \multirow[t]{2}{*}{ G } & \multirow[t]{2}{*}{$\mathbf{T}$} & \multirow{2}{*}{$\begin{array}{c}\text { MW } \\
\text { g/mole }\end{array}$} & \multirow{2}{*}{$\begin{array}{c}\text { ODI } \\
\mathrm{ml}\end{array}$} & \multicolumn{2}{|c|}{ Concentration } & \multirow{2}{*}{$\begin{array}{l}\mathrm{Tm} \\
\left({ }^{\circ} \mathrm{C}\right.\end{array}$} \\
\hline & & & & & & & & & & & & pmol & $\mu \mathrm{g}$ & \\
\hline DTLSH13 & DNA & $x$ & DFLSH7-F & AAC GAA ACC AAA AAT ATC TTA CC & 23 & 12 & 6 & 1 & 4 & 6973 & 9.4 & $44,485.9$ & 310.2 & 60 \\
\hline DTLSH14 & DNA & $x$ & DFLSH7-R & AGG CAG TGA TGT ATC AGC TG & 20 & 5 & 3 & 7 & 5 & 6242 & 7.1 & $37,833.0$ & 234.3 & 60 \\
\hline DTLSH15 & DNA & $x$ & DFLSH8-F & GTA CGA GGA TCT AAA GGT GG & 20 & 6 & 2 & 8 & 4 & 6242 & 7.9 & $41,765.5$ & 260.7 & 60 \\
\hline DTLSH16 & DNA & $x$ & DFLSH8-R & TAC TAA AGC GTG TCT GTG GC & 20 & 4 & 4 & 6 & 6 & 6144 & 7.2 & $38,671.9$ & 237.6 & 60 \\
\hline DTLSH17 & DNA & $x$ & DFLSH9-F & AAT TGT TGC CTT CGT CAG GG & 20 & 3 & 4 & 6 & 7 & 6135 & 9.0 & $48,410.8$ & 297.0 & 60 \\
\hline DTLSH18 & DNA & $x$ & DFLSH9-R & AAC AAA GCC GAG CAA AAC CG & 20 & 10 & 6 & 4 & 0 & 6118 & 10.0 & $53,939.2$ & 330.0 & 60 \\
\hline DTLSH23 & DNA & $\mathrm{x}$ & DFLSH12-F & TCG CTG GAA AAC ACG AAT GG & 20 & 7 & 4 & 6 & 3 & 6171 & 4.9 & $26,203.2$ & 161.7 & 60 \\
\hline DTLSH24 & DNA & $x$ & DFLSH12-R & AAA GCT TAG GGG TTG AGT GG & 20 & 5 & 1 & 9 & 5 & 6273 & 5.2 & $27,355.3$ & 171.6 & 60 \\
\hline
\end{tabular}

Table 3: Custom Oligonucleotide Synthesis Report.

\begin{tabular}{|c|c|c|c|c|}
\hline & Ang Thong & Khon Kaen & Samut Songkhram & Surat Thani \\
\hline AT & 0.000 & & & \\
\hline KK & 0.160 & 0.000 & & \\
\hline SK & 0.147 & 0.149 & 0.000 & \\
\hline SR & 0.173 & 0.162 & 0.197 & 0.000 \\
\hline
\end{tabular}

Table 4: Genetic distance values of giant freshwater prawn population in Thailand.

\section{Conclusion and Suggestions}

In the present development of microsatellite primers in giant freshwater prawns for use in examining the genetic diversity of the prawns, four clones harboring microsatellites were chosen and used in designing four pairs of primers: DTLSH 7, DTLSH 8, DTLSH 9 and DTLSH 12. The primers was utilized to test positive control, unknown prawn samples 1 and 2 and also giant tiger prawn samples. All four primers were able to produce distinct DNA bands of PCR products at the base sequences of $131 \mathrm{bp}$ (DTLSH 7), $174 \mathrm{bp}$ (DTLSH 8), $210 \mathrm{bp}$ (DTLSH 9) and 205 and $193 \mathrm{bp}$ (DTLSH 12). Although the test with these four pairs of primers in different types of prawns yielded equal DNA band values, it is not clear whether they really are identical or different. Choosing and developing primers from each type of prawns are needed for a parallel test for comparison and confirmation. In designing these four pairs of primers in giant freshwater prawns, optimal conditions for their use were determined as demonstrated in Tables 2 and 3. The test results have indicated that the primers are specific to individual locations and yield distinct DNA bands of PCR products. Any pair of primers chosen can give the same readings. Apart from these four pairs, anyone wishing to study and examine the genetic diversity of giant freshwater prawns needs also to use primers developed from additional work by other researchers. Among these other researchers [4], who reported the development of 10 pairs of microsatellite markers in giant freshwater prawns in Thailand, thus obtaining results that are correct and matching the examining requirements. In addition, prawn samples to use in studies should be taken from a variety of sources.

The classification of giant freshwater prawn population in Thailand shows low-level genetic diversity with an average genetic distance of 0.165 . The information on apparent bands of microsatellite DNA has classified the population of these prawns into two groups: one with the closest genetic relationship, namely those from Khon Kaen, Samut Songkhram and Ang Thong, and the other with similar genetic characteristics, namely those from Surat Thani. These findings are consistent with the geographical distances.

\section{Acknowledgement}

The present research was Partially Sponsored by the Center of Excellence on Agricultural Biotechnology, Science and Technology Postgraduate Education and Research Development Office (PERDP), Commission on Higher Education, Ministry of Education and Agricultureal Biotechnology Research Center for Sustainable Economy, Khon Kaen University, the Forty-Year Research Fund of Khon Kaen University, which allocated a budget to assist in research practice of new researchers for the fiscal year 2006. On this occasion, the research team would like to thank this Fund for providing the financial support, organizing the training for new researchers, supporting research presentation and giving advice in the course of the research.

\section{References}

1. Uraiwan S, Sumanojitraporn S, Ampolsak K (2002) Genetic improvement to increase growth rate of giant freshwater prawn (Macrobrachium rosenbergii de Man) 1. Heritability estimates and within-family selection.

2. de Bruyn M, Wilson JA, Mather PB (2004a) Huxley's line demarcates extensive genetic divergence between eastern and western forms of the giant freshwater prawn, Macrobrachium rosenbergii. Mol Phylogenet Evol 30: 251-257.

3. Chand V, de Bruyn M, Mather PB (2005) Microsatellite loci in the eastern form of the giant freshwater prawn (Macrobrachium rosenbergii). Mol Ecol Not 5: 308-310.

4. Charoentawee K, Poompuang S, Na-Nakorn U (2006) Isolation and 
Citation: Charoenwattanasak S, Petkham R, Srisathapom A, Niamphithak P (2015) The Development and Application of Genetic Markers for Giant Freshwater Prawns Macrobrachium Rosenbergii by Microsatellites. J Aquac Res Development 6: 295. doi:10.4172/2155-9546.1000295

characterization of microsatellites in giant freshwater prawn Macrobrachium resenbergii. Mol Ecol Not 6: 823-825.

5. Sambrook J, Fritsch EF, Maniatis T (1989) Molecular Cloning: A Laboratory Manual. Cold Spring Harbor Laboratory Press, Cold Spring Harbor, Newyork.

6. Sneath PHA, Sokal RR (1973) Numerical taxonomy. W. H. Freeman and Company, San Francisco.

7. Daungwongsa J (2003) Genetic variation in population of giant freshwater prawn (Macrobrachium rosenbergii de Man) in Thailand and Myanmar using DNA fingerprint by RAPD technique. A thesis submitted in partial fulfillment of the requirements for the degree of master of science in fisheries, Graduate school Khon Kaen University, Thailand.

8. Saitou N, Nei M (1987) The neighbor-joining method: A new method for reconstructing phylogenetic trees. Mol Biol Evol 4: 406-425.

9. Peyachoknagul S (2009) DNA markers: from basic to application. Kasetsart University Press, Bangkok. 